BEATRIZ MARIA VELOSO PEREIRA

\title{
CARACTERIZAÇÃO DOS EFEITOS DA DIETA HIPERLIPÍDICA NOS RINS DE CAMUNDONGOS DEFICIENTES EM ADIPONECTINA
}

Dissertação apresentada ao Programa de Pósgraduação em Farmacologia do Instituto de Ciências Biomédicas da Universidade de São Paulo, para obtenção do Título de Mestre em Ciências.

Área de concentração: Farmacologia

Orientadora: Profa. Dra. Alice Cristina Rodrigues

Versão original

São Paulo 


\section{RESUMO}

Pereira Veloso BM. Caracterização dos efeitos da dieta hiperlipídica nos rins de camundongos deficientes em adiponectina. [dissertação (Mestrado em Farmacologia)] Instituto de Ciências Biomédicas, Universidade de São Paulo, São Paulo, 2019.

A obesidade é um fator de risco independente para desenvolvimento de doença renal crônica, uma condição caracterizada por progressiva diminuição na função renal e aumento da presença de proteínas na urina. A fisiopatologia da doença renal induzida pela obesidade é complexa, mas evidências sugerem que ela está, em parte, conectada a alterações nos hormônios produzidos e secretados pelo tecido adiposo tais como a adiponectina. Sabendo que a adiponectina possui efeitos nefroprotetores, mas que está diminuída na obesidade, o objetivo desse estudo foi avaliar se a adipocina está envolvida nas alterações renais induzidas pela obesidade. Para tal, utilizamos animais C57BL/6 wild-type (WT) e knockout para adiponectina (AdipoKO) alimentados com dieta controle ou hiperlipídica (modelo de obesidade). Os resultados obtidos indicam que sistemicamente os animais WT e AdipoKO respondem de maneira similar à obesidade. Por outro lado, nos rins, a falta de adiponectina per se levou ao: aumento da expressão gênica de $F a b p 4$, pior progressão da albuminúria, redução da expressão gênica de Cptla e aumento do miR-130b. Mais importante, a falta de adiponectina somada à obesidade promove diminuição na expressão proteica de nefrina e exacerbação da albuminúria. Curiosamente, a falta de adiponectina não parece levar a piora da esteatose renal provocada pela dieta hiperlipídica. Considerados em conjunto, esses resultados indicam que a falta de adiponectina influencia na diminuição da função renal (caracterizada pela albuminúria) mas não é significativa no acúmulo de lipídeos observados no rim obeso durante o período estudado.

Palavras Chave: Adiponectina. Albuminúria. Dieta hiperlipídica. Obesidade. 


\begin{abstract}
Pereira Veloso BM. Characterization of high-fat diet effects on the kidney of adiponectin deficient mice. [dissertation (Master thesis in Phamacology)] - Instituto de Ciências Biomédicas, Universidade de São Paulo, São Paulo, 2019.

Obesity is an independent risk factor to develop chronic kidney disease, a condition characterized by a progressive decrease in renal function and increased presence of proteins in the urine. The pathophysiology of the obesity-induced kidney injury is complex, but evidences suggest that it is partly connected to alterations in the hormones produced and secreted by adipose tissue such as adiponectin. Considering that adiponectin has nephroprotective effects but it is reduced in obesity, this study aimed to investigate the role of adiponectin in renal injury associated with obesity. For this purpose, we used C57BL/6 mice wild-type (WT) and knockout to adiponectin (AdipoKO) fed with control or high-fat diet (obesity model). Data provide herein indicate that systemically WT and AdipoKO mice respond similarly to obesity. On the other hand, in the kidneys, the lack of adiponectin per se led to: increased gene expression of Fabp4, worse progression of albuminuria, reduced gene expression of $C p t 1 a$ and increased in miR-130b. More importantly, adipoKO mice fed with high-fat diet had decreased nephrin expression and exacerbation of albuminuria. Interestingly, the lack of adiponectin does not seem to worsen renal steatosis caused by the high-fat diet. Considered together, these results indicate that the lack of adiponectin influences the decrease in renal function (characterized by albuminuria) but is not significant to the accumulation of lipids observed in the obese kidney during the period studied.
\end{abstract}

Key words: Adiponectin. Albuminuria. High-fat diet. Obesity. 


\section{INTRODUÇÃO}

Nas últimas décadas, têm se evidenciado um aumento alarmante na prevalência mundial de obesidade, resultante do desbalanço entre calorias consumidas e calorias gastas. Esse desequilíbrio é consequência de um estilo de vida mais sedentário e crescente consumo de alimentos ricos em energia levando a um acúmulo anormal ou excessivo de gordura, característico da obesidade (1).

Para ser classificado obeso, o indivíduo é avaliado quanto a sua adiposidade corporal. Para isso, calcula-se seu índice de massa corporal (IMC). O IMC é o resultado da divisão do peso em $\mathrm{kg}$ pela altura em metros elevada ao quadrado $\left(\mathrm{kg} / \mathrm{m}^{2}\right)$. Indivíduos com IMC igual ou acima de $30 \mathrm{~kg} / \mathrm{m}^{2}$ são considerados obesos (Tabela 1). No entanto esse índice não leva em conta a massa magra nem a distribuição da gordura corporal. Considerando que o aumento de gordura visceral (intra-abdominal) é um fator de risco potencial para doenças, independentemente da gordura corporal total, é importante também ser feita a medição da circunferência abdominal (2).

Tabela 1. Classificação internacional da obesidade segundo o índice de massa corporal (IMC) e risco de doença.

\begin{tabular}{|c|c|c|c|}
\hline Classificação & & IMC & Risco de doença \\
\hline Peso normal & & $18.5-24.9 \mathrm{~kg} / \mathrm{m}^{2}$ & Normal \\
\hline Sobrepeso ou pré-obeso & & $25-29.9 \mathrm{~kg} / \mathrm{m}^{2}$ & Aumentado \\
\hline Obesidade grau I & & $30-34.9 \mathrm{~kg} / \mathrm{m}^{2}$ & Moderado \\
\hline Obesidade grau II & & $35-39.9 \mathrm{~kg} / \mathrm{m}^{2}$ & Severo \\
\hline $\begin{array}{l}\text { Obesidade grau III } \\
\text { obesidade mórbida }\end{array}$ & ou & $\geq 40 \mathrm{~kg} / \mathrm{m}^{2}$ & Muito severo \\
\hline
\end{tabular}

Fonte: Organização mundial de saúde (OMS) (3)

De acordo com estatísticas da OMS, a prevalência mundial da obesidade quase triplicou entre 1975 e 2016. Em 2016 mais de 1,9 bilhões de adultos estavam acima do peso e desses 650 milhões estavam obesos. Entre crianças e adolescentes (5-19 anos) mais de 340 milhões estão em uma dessas condições (1).

Essa pandemia além de causar problemas individuais, afeta a sociedade e sobrecarrega os sistemas de saúde. Indivíduos obesos geralmente apresentam incapacidade funcional, diminuição da qualidade e expectativa de vida, além de 
problemas de ajustes sociais e redução da produtividade implicando em um gasto público que vai além dos custos médicos (4).

Todas essas consequências são causadas não só pelo aumento da adiposidade mas pelas complicações associadas. O aumento nas taxas de obesidade tem levado também ao aumento de comorbidades associadas à obesidade (5). Isso porque a obesidade é uma condição complexa que pode afetar a função de vários órgãos, sendo considerada fator de risco para uma ampla gama de distúrbios cardiometabólicos incluindo doença coronariana, hipertensão e acidente vascular cerebral, diabetes tipo 2 , dislipidemia, doença hepática gordurosa não alcoólica, doenças pulmonares incluindo apneia do sono além de certos tipos de câncer $(6,7)$.

Além das já conhecidas consequências da obesidade sobre orgãos como coração, fígado e pulmão, tem se destacado os efeitos da obesidade nos rins $(5,8,9)$. A importância da relação obesidade-doença renal foi destacada no Dia Mundial do Rim de 2017 (10). Com o tema "DOENÇA RENAL \& OBESIDADE" ESTILO DE VIDA SAUDÁVEL PARA RINS SAUDÁVEIS", a sociedade internacional de nefrologia buscou chamar atenção da população para essa causa de doença renal que pode ser prevenida (11).

\subsection{Rins e Função Renal}

Os rins são órgãos chave para prevenir o acúmulo de produtos residuais do metabolismo e fármacos, manter constante a composição e o volume do compartimento extracelular apesar das grandes variações qualitativas e quantitativas na ingestão de solutos e água ao longo do dia e produzir hormônios como eritropoietina, renina e vitamina D (12).

Para exercer suas funções ele conta com uma organização celular altamente especializada. As unidades funcionais dos rins são os néfrons que estão distribuídos no córtex e medula renal (Figura 1). De modo geral, cada um dos milhares à milhões de néfrons presentes nos rins apresentam em sua estrutura duas partes principais: uma inicial, chamada de corpúsculo renal, onde ocorre uma filtração inicial do sangue que chega aos rins; e uma subsequente, os túbulos renais onde ocorrem os processos de reabsorção e secreção do filtrado, até a excreção final da urina (12). 
Figura 1. Ilustração dos rins, distribuição do néfron no tecido renal e suas partes principais.

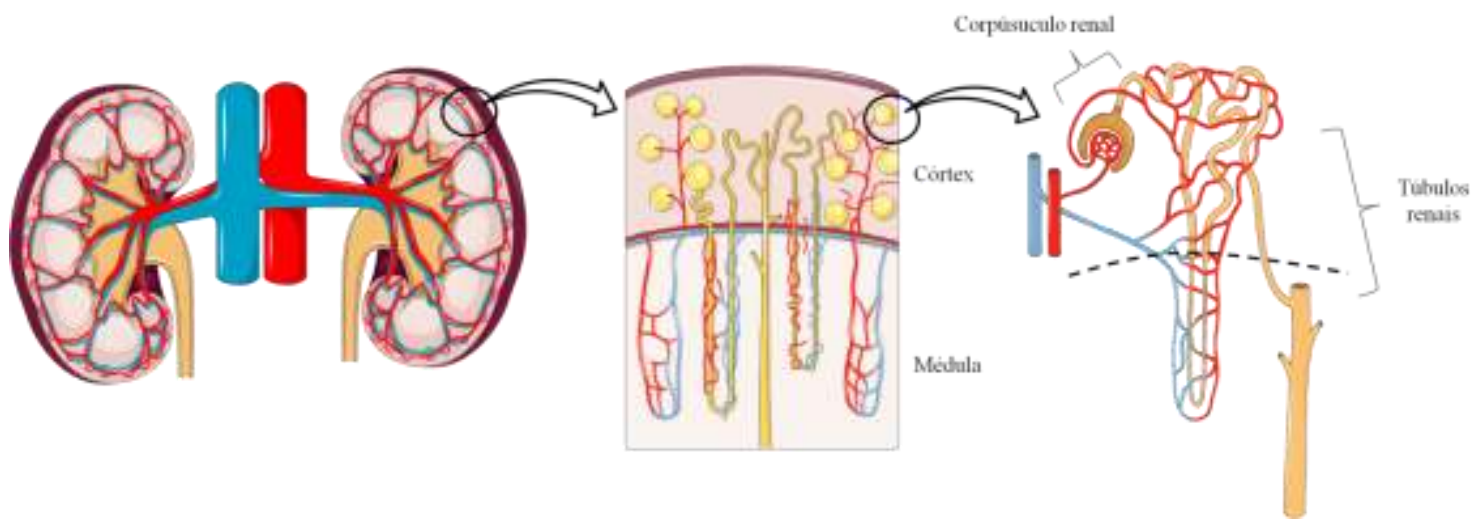

O néfron é a unidade funcional do rim. Nele há o processo de filtração do sangue, reabsorção e secreção de substâncias até a excreção final da urina. Os corpúsculos renais e os túbulos renais se encontram no córtex e podem descer para a medula renal.

A parte inicial do néfron ou corpúsculo renal é formado pelo glomérulo e a cápsula de Bowman. Entre eles há um espaço, conhecido como espaço capsular ou lúmen da cápsula de Bowman. O glomérulo, a unidade de filtração do rim, é composto por uma rede de capilares - proveniente da arteríola aferente e que desemborca na arteríola eferente - e células epiteliais especializadas e terminalmente diferenciadas, chamadas de podócitos, os quais envolvem esses capilares. Além dos capilares e podócitos, o glomérulo conta com as células mesangiais, que se localizam entre as alças dos capilares, e produzem um material amorfo chamado de matriz mesangial, responsáveis pela sustentação do glomérulo e função contrátil $(12,13)$ (Figura 2). 
Figura 2. Componentes glomerulares.
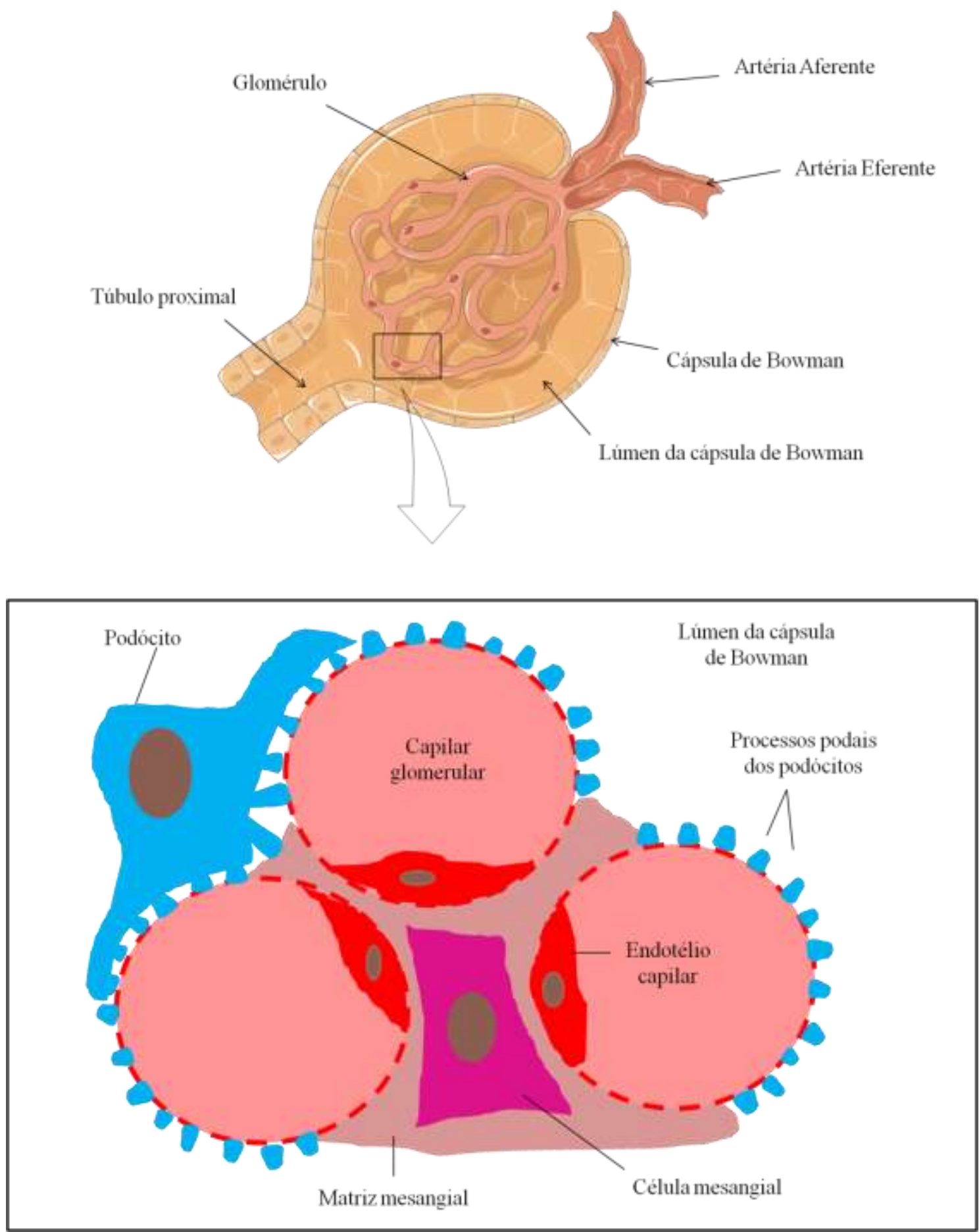

O glomérulo se encontra dentro da cápsula de Bowman e é formado pelos capilares glomerulares, podócitos, células mesangiais e matriz mesangial.

O plasma sanguíneo presente no lúmen dos capilares glomerulares enfrenta, passivamente, uma barreira de ultrafiltração até que alcance o lúmen da cápsula de Bowman como filtrado glomerular ou urina primitiva. Essa barreira de ultrafiltração possui três estruturas e são elas: células endoteliais fenestradas dos capilares, membrana basal glomerular (MBG) e podócitos com suas junções especializadas ou fenda 
diafragmática (14) (Figura 3). Juntos, esses componentes impedem fisicamente (seleção por tamanho) e eletroquimicamente (repulsão de cargas) a saída de macromoléculas do sangue, garantindo a retenção de proteínas grandes no plasma, como a albumina (66 kDa) (15). Finalmente, o ultrafiltrado resultante, quase livre de proteínas, segue do lúmen da cápsula de Bowman para os túbulos renais para ajuste fino do que deve ou não ser excretado na urina. No túbulo proximal, a maior parte das proteínas de baixo peso molecular que ainda passou para o filtrado são reabsorvidas e assim apenas traços de proteínas são excretados na urina (16).

Figura 3. Representação da barreira de filtração glomerular.

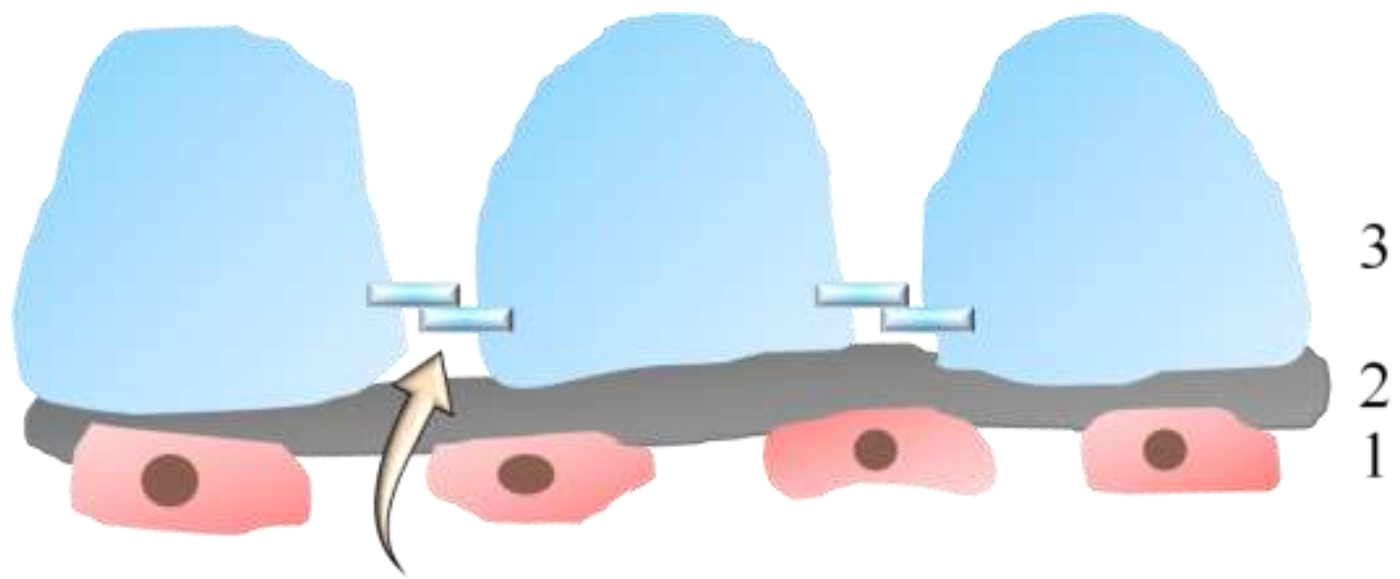

Os números 1, 2 e 3 indicam os componentes da barreira. 1 - endotélio fenestrado; 2 membrana basal glomerular; 3- processos podais dos podócitos e fenda diafragmática.

Uma vez que a barreira de filtração sofre lesão ou aumenta sua permeabilidade, seja por danos em podócitos ou em seus outros componentes, ela perde a capacidade de selecionar adequadamente o conteúdo do filtrado, o que pode resultar em maior passagem de proteínas como a albumina (presente em altas concentrações no plasma) para a urina, processo chamado de albuminúria. A perda de albumina na urina é apresentação comum em doenças renais. A membrana basal glomerular, situada entre células endoteliais e podócitos, é formada por uma "rede" de glicoproteínas e proteoglicanos e fornece a primeira estrutura de suporte ao tufo glomerular. O espessamento dessa membrana está associada à albuminúria (17). Adicionalmente, os podócitos, intimamente associados aos capilares e à $\mathrm{MBG}$, estão vulneráveis às mudanças metabólicas e pressões hemodinâmicas (18).

Os podócitos possuem uma organização celular única e complexa, com três segmentos citoarquitetônicos diferentes: corpo celular, processos principais e processos 
podais (Figura 4) que são regularmente separados, mas conectados por uma fenda diafragmática caracterizada por uma malha de proteínas ancoradas na parte inferior das suas laterais $(17,19)$. São os processos podais que envolvem os capilares e a fenda diafragmática que atuam na barreira de ultrafiltração glomerular.

A resposta dos podócitos à injúria é determinada por suas alterações moleculares e ultraestruturais. Dependendo da gravidade e da duração da injúria, as alterações nas funções dos podócitos podem evoluir para um quadro de alteração na filtração glomerular e albuminúria (20,21). Por exemplo, redução na expressão de nefrina e podocina, duas das proteínas presentes na fenda diafragmática resulta na perda dos podócitos e isso está associado à albuminúria e glomeruloesclerose (22).

Considerando que podócitos são células com capacidade limitada para divisão celular e substituição, a perda de alguns podócitos exige que as células residuais cubram uma área maior de MBG. Consequentemente isso pode causar o alargamento dos processos podais e reduzir a capacidade dos podócitos de permanecerem presos à MBG. A área descoberta resultante desse processo é um potencial ponto de início para deposição de matriz resultando em glomeruloesclerose em modelos experimentais bem como em biópsias humanas (5). Processo similar acontece no caso de hipertrofia glomerular, visto por exemplo na obesidade, uma vez que os podócitos precisam cobrir uma área maior expandindo os processos podais. Se esse aumento não for proporcional à hipertrofia glomerular isso pode levar ao descolamento do podócito (23). Em caso de persistência da injúria, o tecido normal acaba sendo substituído por tecido fibrótico, o que leva perda funcional da região afetada (24).

\section{Figura 4. Microscopia eletrônica de varredura do glomérulo.}

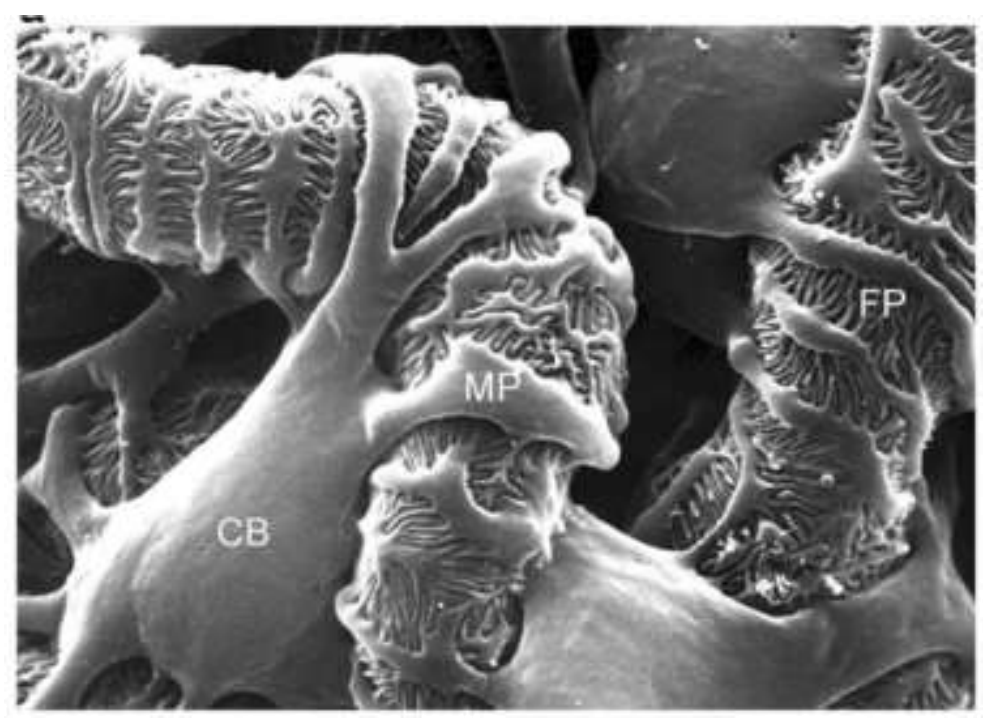

Fonte: Mundel (25) 
Destaca-se três segmentos dos podócitos: um corpo celular (CB, do inglês cell body), processos principais (MP, do inglês major processes) e processos podais (FP, do inglês foot processes).

\subsection{Doença renal crônica}

A doença renal crônica (DRC) é uma condição caracterizada por progressiva anormalidade na função e/ou estrutura renal, presentes por mais de três meses, com implicações para a saúde que podem ser muitas vezes irreversíveis $(26,27)$. Embora a DRC possa resultar de uma variedade de causas etiologicamente distintas (28), o diabetes e a hipertensão arterial são atualmente as principais causas de DRC $(28,29)$.

A presença persistente de proteínas na urina $(26,30)$ e/ou diminuição do ritmo de filtração glomerular indicam DRC (15,31). A taxa de filtração glomerular (RFG) normal média é 90-120 mL/min (31). Entre as classificações da DRC estão as por categoria de RFG e por albuminúria. De acordo com a National Kidney Foundation, RGF categoriza a DRC em 5 estágios: Estágio 1) lesão inicial, com função renal preservada - RFG acima ou igual a $90 \mathrm{~mL} / \mathrm{min} / 1,73 \mathrm{~m}^{2}$; 2) início da perda da função renal - RFG entre 60 e $89 \mathrm{~mL} / \mathrm{min} / 1,73 \mathrm{~m}^{2}$; 3) injúria renal moderada - RFG entre 30 e $59 \mathrm{~mL} / \mathrm{min} / 1.73 \mathrm{~m}^{2}$, com concentrações plasmáticas elevadas de ureia e creatinina (substâncias resultante do metabolismo de proteínas relativamente constantes e estavelmente excretadas na urina) (12); 4) injúria renal grave - RFG entre 15 e $29 \mathrm{~mL} / \mathrm{min} / 1.73 \mathrm{~m}^{2}$, paciente com hipertensão arterial e edema; 5) fase terminal da DRC - RFG menor que 15 $\mathrm{mL} / \mathrm{min} / 1,73 \mathrm{~m}^{2}$ - nessa condição, o paciente passa a depender de terapia de substituição renal como diálise ou transplante renal (31). Já a classificação por albuminúria é dividida em 3 categorias: Normal ou suavemente aumentada - albuminúria menor que $30 \mathrm{mg} / \mathrm{g}$ de creatinina ( $\mathrm{Cr}$ ); moderadamente aumentada (também chamada microalbuminúria) - albuminúria entre 30 e $300 \mathrm{mg} / \mathrm{g} \mathrm{Cr}$; severamente aumentada albuminúria maior que $300 \mathrm{mg} / \mathrm{g} \mathrm{Cr}$. A eventual perda da capacidade renal de filtrar o sangue adequadamente resulta no acúmulo de resíduos metabólicos, desequilíbrio hidroeletrolítico e danos sistêmicos (26).

\subsection{Obesidade e doença renal crônica}

A obesidade não só está fortemente associada as duas principais causas de DRC, hipertensão e diabetes, mas também é um fator de risco independente para o desenvolvimento da DRC, doença renal em estágio terminal e para progressão de 
doença renal crônica (32-34). A primeira associação entre obesidade massiva e albuminúria foi reportada em 1974 (35). Evidências sugerem que, em geral, o aumento do risco de DRC e DRC em fase terminal cresce com o aumento do IMC (33).

Os efeitos renais da obesidade em animais experimentais e humanos incluem ambas (mal)adaptações estruturais e funcionais. Embora incompletamente compreendido, alterações em vários fatores hemodinâmicos (RFG, fluxo plasmático renal, fração de filtração), hormonais e metabólicos têm sido apontados como contribuintes na patogênese da nefropatia associada à obesidade. Potenciais mecanismos incluem hiperfiltração, aumento da pressão glomerular, hiperinsulinemia/resistência à insulina, dislipidemia, metabolismo lipídico renal anormal, hiperatividade do sistema renina-angiotensina-aldosterona, inflamação associada à obesidade (aumento de citocinas e moléculas pró-inflamatórias), desbalanço de adipocinas (por exemplo, alta leptina e baixa adiponectina) e estresse oxidativo $(8,9,11,32,36)$.

Histologicamente, a obesidade tem sido associada à glomeruloesclerose segmentar e focal (GESF) secundária chamada de glomerulopatia associada à obesidade (ORG) (34). Em 2001, foi publicado o primeiro grande estudo clínico-patológico sobre glomerulopatia relacionada à obesidade baseado em biópsias renais realizadas entre 1986 e 2000 (9). O critério para um diagnóstico de ORG era IMC $\geq 30 \mathrm{~kg} / \mathrm{m}^{2}$ e presença de glomerulomegalia (hipertrofia glomerular) com ou sem GESF (padrão histológico de lesão fibrótica que é focal [menos da metade de todos os glomérulos estão afetados] e segmentar [menos de 50\% do tufo glomerular é afetado]) (37). A GESF secundária à obesidade se mostrou morfológica e clinicamente diferente da GESF de causa idiopática. Na ORG, foi observado menor porcentagem de glomérulos afetados por esclerose segmentar, menor grau de perda de processos podais e presença mais consistente de glomerulomegalia (9). Além disso, os pacientes têm menor incidência de síndrome nefrótica, curso mais benigno e menor progressão para a insuficiência renal. De acordo com a revisão de D’Agati (38) a apresentação clínica mais característica da ORG é albuminúria isolada com ou sem comprometimento renal. Outros achados como hipertensão e dislipidemia são frequentes. Vale ser destacado que o risco de desenvolver ORG não é uniforme na população obesa (7). Susceptibilidade do rim à obesidade parece depender de fatores (epi)genéticos $(15,39)$ e número de néfrons no nascimento $(36,41)$.

Para investigar os mecanismo da injúria glomerular na ORG, Wu et al. (41) estudaram o perfil de expressão gênica nos glomérulos obtidos de biópsias renais de 
pacientes com ORG. Eles observaram que genes principalmente envolvidos no metabolismo lipídico, citocinas inflamatórias e resistência à insulina foram os que mais se destacaram significativamente nos pacientes com ORG em comparação aos controles.

Em modelos animais de obesidade, especialmente obesidade induzida por dieta hiperlipídica, também se observa albuminúria, glomerulomegalia, expansão de matriz mesangial, espessamento da MBG, glomeruloesclerose, aumento de moléculas fibróticas (colágeno IV, inibidor do ativador de plasminogênio tipo 1 [PAI-I] e fator de crescimento endotelial vascular [VEGF]), acúmulo de lipídeos nas células renais além de aumento da inflamação e estresse oxidativo (42-45).

\subsection{Acúmulo ectópico de lipídeos e doença renal crônica}

Acumulação lipídica ectópica refere-se ao acúmulo de gordura em tecidos nãoadiposos como músculo, fígado, rins e pâncreas resultante de uma ingestão de energia que excede gradualmente a capacidade do corpo de armazenar gordura no tecido adiposo (tecido adiposo branco) (46). Nos rins, onde o metabolismo lipídico normal é essencial para a fisiologia renal, distúrbios do metabolismo lipídico renal e energético estão cada vez mais associados à doença renal (32). O acúmulo de lipídeos pode ser observado em células mesangiais, podócitos e células epiteliais do túbulo proximal, essas últimas parecem ser particularmente mais susceptíveis ao dano pela desregulação do metabolismo lipídico normal uma vez que a maior fonte de energia provém da $\beta$ oxidação dos ácidos graxos $(47,48)$.

Particularmente, a homeostase dos ácidos graxos é regulada por um complexa interação que de um lado está captação de ácidos graxos não-esterificados (ou ácidos graxos livres) do plasma e ácidos graxos de novo e do outro está $\beta$-oxidação de ácidos graxos e exportação via lipoproteínas $(48,49)$. A esteatose renal ocorre quando a taxa de entrada de ácidos graxos (captação e síntese) excede a taxa de saída (oxidação e secreção) (Figura 5) (49,50). Na maioria dos estudos em animais com nefropatia induzida por dieta hiperlipídica, o metabolismo lipídico renal alterado culmina no acúmulo de ácidos graxos em forma de triglicerídeos (TG; 3 moléculas de ácidos graxos esterificados com glicerol) causado por diminuição de enzimas de oxidação de ácidos graxos e aumento de enzimas envolvidas na lipogênese (51). Porém há estudos que evidenciaram acúmulo de outros lipídeos como colesterol e fosfolipídeos (52). 
Figura 5. O conteúdo de ácido graxo no rim é resultado principalmente dos processos de entrada, síntese e oxidação.

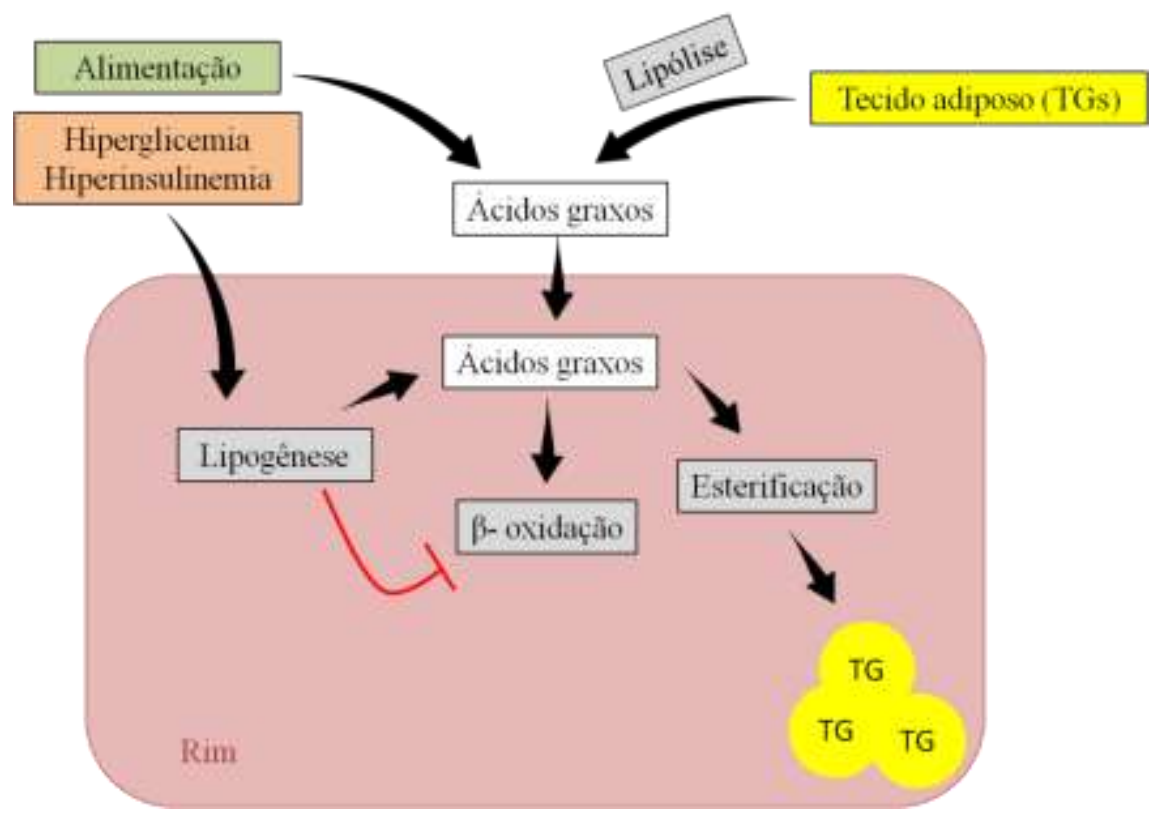

Os ácidos graxos que chegam aos rins incluem os derivados da lipólise dos triglicerídeos (TGs) do tecido adiposo branco e os ingeridos na dieta. Dentro do rim a síntese de novo de ácidos graxos pode ser resultado do excesso da metabolização de glicose. Esses ácidos graxos podem ser posteriormente utilizados como fonte de energia através da sua oxidação bem como podem ser esterificados e armazenados como TGs.

Diversos estudos em animais, inclusive em modelos de obesidade induzida por dieta hiperlipídica, têm demostrado que o acúmulo ectópico de lipídeos está envolvido nas mudanças estruturais e funcionais das células renais na obesidade $(34,42,44,48,51)$. Ao mesmo tempo tem se observado redução significativa do acúmulo de lipídeos e de fatores implicados na glomeruloesclerose e albuminúria, quando os animais foram tratados com fenofibrato (agonista do fator de transcrição receptor $\alpha$ ativado por proliferador de peroxissoma [PPAR $\alpha]$ ) (53), estatinas (54), AICAR e metformina (ativador da proteína quinase ativada por adenosina monofosfato [AMPK]) $(55,56)$, doxercalciferol (agonista do receptor de vitamina D) (57), INT-747 (agonista do receptor farnesóide X), INT-777 (agonista do TGR5 [do inglês G-protein-coupled bile acid receptor]) (58) e Silimarina (59), todos os quais modulam em diferentes extensões vias de metabolismo lipídico (60). Em adição às intervenções farmacológicas citadas, manipulação genética direcionada a fatores de transcrição envolvidos na síntese de lipídios como por exemplo, deleção do gene da proteína de ligação a elemento regulador de esterol 1c (SREBP-1c ${ }^{-/-}$) (42) e deleção parcial de receptor ativado por proliferador 
de peroxissoma- $\gamma\left(\right.$ PPAR $^{(+/)}{ }^{(-)}$(51) mostraram melhora no acúmulo de lipídeos bem como na injúria renal histológica ou funcional induzidos pela dieta hiperlipídica. A deleção do cluster de diferenciação $36\left(\mathrm{CD}_{3} 6^{-/-}\right.$; o principal sistema de captação de ácidos graxos nos rins), reverteu o acúmulo de lipídeos renal em camundongos obesos com inflamação (dieta hiperlipídica + caseína) e preveniu o desenvolvimento de lesão renal (49).

Outras evidências das consequências do metabolismo lipídico alterado e acúmulo de lipídeos nos rins foram vistas em dois estudos de Chen et al. (61,62). Em ambos estudos, os pesquisadores evidenciaram um importante papel da enzima lipase de TG de tecido adiposo (ATGL) no conteúdo lipídico renal in vivo e in vitro (podócitos e células do túbulo proximal). A ATGL participa da etapa limitante para iniciação do catabolismo de TG - promove remoção de um ácido graxo da molécula, gerando um ácido graxo livre e um diglicerídeo. Animais deficientes em ATGL exibiram menor expressão de PPARa nas células tubulares do rim, acúmulo de TG nos podócitos e células do túbulo proximal e albuminúria em comparação com os animais wild-type.

Como descrito acima, vários estudos em animais têm sugerido que o acúmulo de lipídeos e lipotoxicidade têm um importante papel na fisiopatologia da doença renal na obesidade. Em 2014, Bobulescu et al. (63) mostraram pela primeira vez, em humanos, que a obesidade está associada com aumento do acúmulo de TGs nos rins, predominantemente nas células tubulares. No mesmo ano, Herman-Edelstein et al. observaram metabolismo lipídico alterado e acúmulo de lipídeos no rim de humanos com nefropatia diabética. Particularmente, vias de $\beta$-oxidação de ácidos graxos estavam menos ativas, receptores de captação de colesterol estavam aumentados e genes que afetam o efluxo de colesterol diminuídos (64). Kang et al. (65) também observaram oxidação defeituosa de ácidos graxos e acúmulo de lipídeos em células tubulares fibróticas de humanos.

É importante notar que os ácidos graxos armazenados na forma de TG per se não são considerados tóxicos. Por exemplo, Scerbo et al. (66) mostrou acúmulo de lipídeos nos rins em situação não-patológica. Nesse estudo, os animais passaram um período de jejum de 16 horas. Ao analisar os rins, foi observado maior entrada de ácidos graxos, os quais eram oxidados na mitocôndria ou eram estocados como TGs. Porém esse processo não foi associado com metabólitos tóxicos (66). No entanto, em outras situações como por exemplo oxidação de ácidos graxos prejudicada, o conteúdo intracelular excessivo de ácidos graxos livres não metabolizados pode potencialmente 
resultar na formação de metabolitos tóxicos tais como diacilgliceróis e ceramidas. Esses últimos podem levar a estresse oxidativo, disfunção mitocondrial, e subsequentemente piorar a capacidade de oxidação dos ácidos graxos, causando mais acúmulo de gordura ao mesmo tempo que promove deficiência energética na célula (67).

\subsection{Comunicação entre tecido adiposo e rins: adiponectina e seu papel nefroprotetor}

O tecido adiposo não só tem grande impacto no armazenamento de energia em forma de gordura, termogênese e homeostase metabólica como também tem funções imunológicas e endócrinas uma vez que produz e secreta substâncias bioativas, tais como citocinas e adipocinas. Entre as adipocinas estão leptina, adiponectina, visfatina, resistina e outras. Na obesidade há desregulação na produção e secreção de algumas adipocinas, o que além de contribuir para observada disfunção imune e metabólica, tem impacto sobre a função renal $(5,16)$.

A adiponectina é um polipeptídio de 30kDa descrito primeiramente em 1995 (68) que exerce efeitos anti-inflamatórios, antioxidantes, anti-ateroscleróticos e de sensibilização à insulina (69). No soro, a adiponectina é encontrada em concentrações consideráveis (5 a $30 \mu \mathrm{g} / \mathrm{mL}$ ) (70) e circula em uma variedade de formas multiméricas tais como trímeros, hexâmeros (baixo e médio peso molecular) e complexos de alto peso molecular (71). Embora seja secretada predominante no tecido adiposo, baixos níveis de adiponectina (RNAm e proteína) têm sido detectado em outros tipos celulares tais como osteoblastos (72), hepatócitos (73), miotubos (74), cardiomiócitos (75), células tubulares renais (76) e outros (77-79), em geral, após tratamento com citocinas inflamatórias ou outros estressores. No entanto, sugere-se que essa produção "ectópica" atue de maneira autócrina/parácrina (71).

A sinalização da adiponectina é complexa e tipo célula/tecido-específica. Acredita-se que muitos de seus efeitos pleiotrópicos sejam mediados principalmente via os receptores de adiponectina 1 e 2 (AdipoR1 e AdipoR2) (71). Adicionalmente, Tcaderina e PAQR3 (do inglês, Progestin And AdipoQ Receptor Family Member 3) também têm sido descritas como proteínas ligadoras de adiponectina envolvidas na mediação de seus efeitos $(80,81)$. Os receptores AdipoR1 e AdipoR2 são expressos por uma ampla variedade de tecidos. Nas células tubulares renais humanas e podócitos é 
encontrado ambos AdipoR1 e AdipoR2, no entanto há predominância de AdipoR1 no $\operatorname{rim}(82,83)$.

A interação da adiponectina com seus receptores AdipoR1 e AdipoR2 promove uma sinalização intracelular que inclui proteínas que interagem diretamente com os receptores de adiponectina tais como APPL1, que funciona como intermediária de sinalização, e proteínas efetoras mais distais (71). Um número de quinases intracelulares são ativadas pela ligação da adiponectina aos seus receptores, entre elas a AMPK, um importante sensor do balanço energético intracelular que regula homeostase de lipídeos e glicose (84). Outra proteína considerada efetora à jusante é o PPAR $\alpha$, um receptor nuclear que aumenta a expressão de genes involvidos no metabolismo de ácidos graxos (85).

Como mencionado acima, a adiponectina exerce seus efeitos via ativação de moléculas sinalizadoras como AMPK. A ativação de AMPK, que se dá pela fosforilação reversível da treonina 172 (p-AMPK), é complexa e pode ser promovida por uma combinação de eventos que incluem uma diminuição na taxa celular de AMP/ATP, fosforilação por quinases à montante e menor acessibilidade à fosfatases (71). Estudos em fígado e músculo mostram que ao ser ativada, a AMPK estimula vias catabólicas que aumentam ATP como $\beta$-oxidação enquanto que diminui o consumo de ATP (p. ex inibindo lipogênese) (Figura 6). Uma vez fosforilada, a p-AMPK fosforila a enzima acetil-CoA carboxilase (ACC), a qual participa da etapa limitante da síntese de ácidos graxos. A fosforilação de ACC na Ser79 leva a redução da sua atividade e consequentemente redução da produção de malonil-CoA, inibidor alostérico da carnitina palmitoiltransferase 1 (CPT-1), enzima que controla a transferência de ácidos graxos de cadeia longa para as mitocôndrias para sua posterior oxidação. Assim, através da fosforilação da ACC, CPT-1 fica mais ativa e mais ácidos graxos de cadeia longa vão ser transferidos para a mitocôndria induzindo a oxidação de ácidos graxos. Além disso, a p-AMPK promove captação de ácidos graxos e oxidação através da maior expressão de genes regulados por ativação do PPAR $\alpha$ tais como as CPTs e reduz a expressão de enzimas lipogênicas, tais como a ácido graxo sintase (FAS), e expressão de SREBP-1, um importante fator de transcrição lipogênico (86,87). No rim, parece ocorrer mecanismo similar (55). 


\section{Figura 6. Representação esquemática simplificada do metabolismo de ácidos graxos de}

acordo com o balanço energético da célula.

A

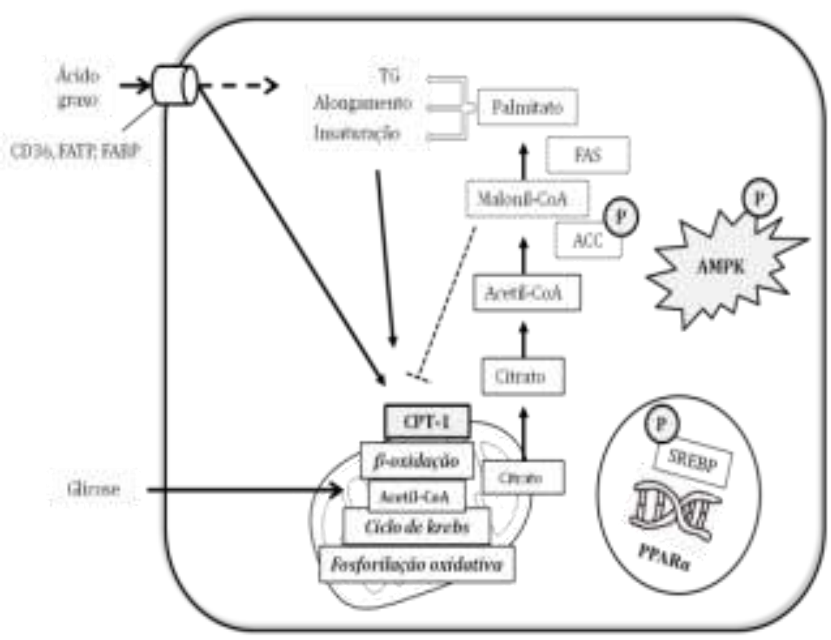

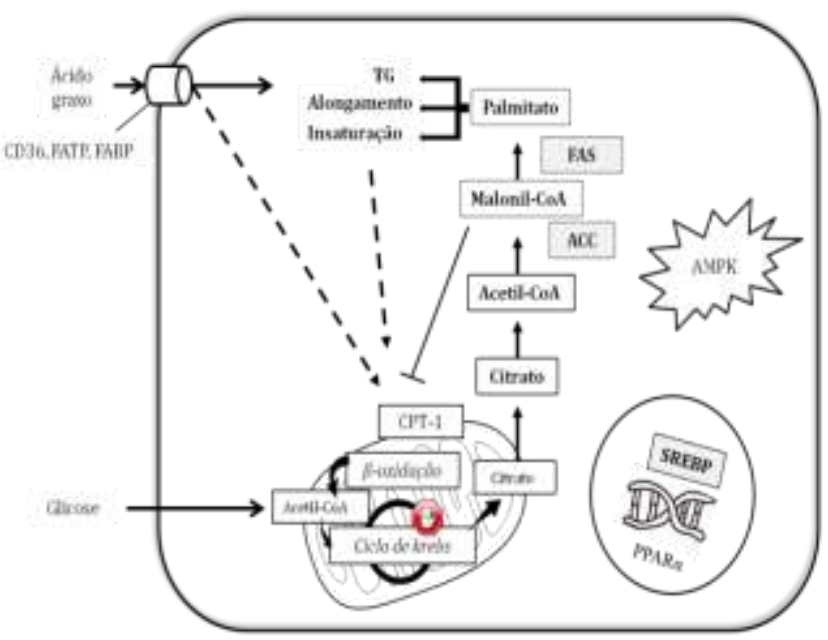

Algumas das vias implicadas no metabolismo dos ácidos graxos estão descritas na figura. A captação de ácidos graxos de cadeia longa é facilitada por proteínas na membrana plasmática como CD36, FATPs, FABPs (46). Dependendo do balanço energético das células esses ácidos graxos captados vão ser metabolizados ou estocados para uso futuro. Adicionalmente, excesso de energia vindo de outras fontes como carboidratos pode promover a síntese de novo de ácidos graxos. A AMPK é uma enzima capaz de sentir a necessidade energética da célula e assim promover uma ou outra via. (A) AMPK é ativada quando a razão AMP/ATP na célula está aumentada, induzindo o catabolismo de ácidos graxos ( $\beta$-oxidação). Para serem metabolizados, os ácidos graxos precisam ser transportados para dentro da mitocôndria, processo mediado pela CPT1. Entre os fatores de transcrição que regulam a expressão de proteínas envolvidas na captação e oxidação de ácidos graxos está PPARa. (B) AMPK fica inativa quando há redução na razão AMP/ATP e predominam vias de síntese e estoque de energia. Nessa situação, enzimas de síntese como ACC e FAS estão ativas bem como esterificação dos ácidos graxos em TG.

A relação adiponectina e função renal é complexa (88). Estudos têm sugerido que início precoce da albuminúria em pacientes com obesidade e hipertensão é associado à concentrações reduzidas de adiponectina no sangue (89-91). Essa diminuição também foi vista em animais sob dieta hiperlipídica, o qual também apresentou redução da atividade de AMPK $(44,51,55,56)$. Por outro lado, as concentrações de adiponectina variam em pacientes com DRC estabelecida e avançada (88). Ainda há estudos em animais que sugerem inibição da sinalização adiponectina/AMPK como alvo terapêutico para doença fibrótica renal (92).

Modelos in vivo e in vitro tem buscado entender o papel da adiponectina no rim em diferentes contextos. Seu papel nefroprotetor parece envolver o controle simultâneo de processos como sinalização celular pró-fibrótica, estresse oxidativo e inflamação no início do desenvolvimento da lesão renal. Sharma et al. (83) observaram que deleção do gene da adiponectina $\left(\mathrm{Adipo}^{-/-}\right.$) leva a albuminúria, dano podocitário e 
estresse oxidativo glomerular. E que o tratamento de podócitos com a adiponectina está associada à ativação de AMPK via AdipoR1 e menores níveis da enzima produtora de superóxido nicotinamida adenina dinucleotídeo fosfato oxidase 4 (NADPH oxidase 4 ou Nox4). Com esse trabalho eles identificaram um papel crítico da adiponectina na manutenção da saúde podocitária via inibição do estresse oxidativo (Figura7).

\section{Figura 7. Representação esquemática dos efeitos da adiponectina sobre os podócitos na} obesidade/deficiência de adiponectina.

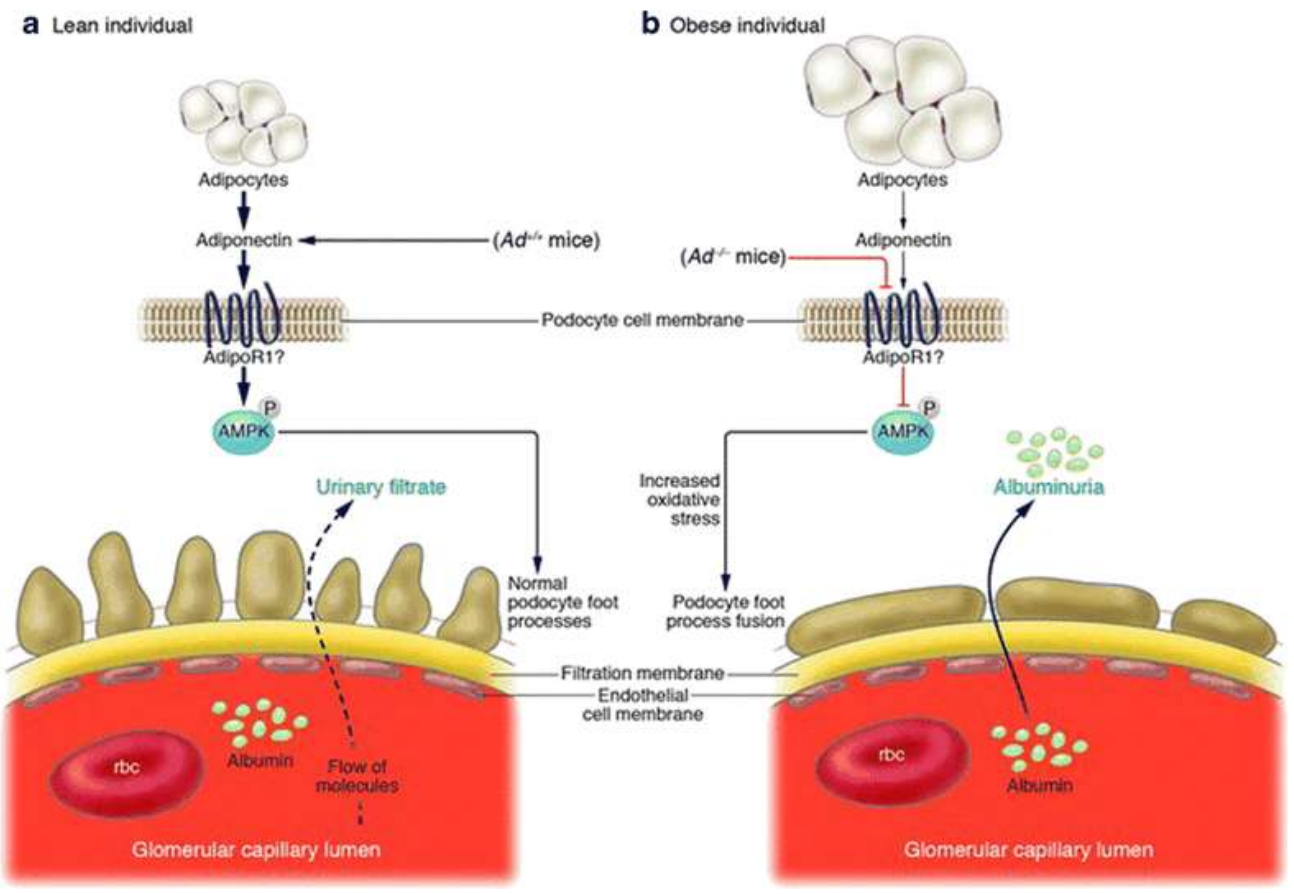

Fonte: Ahima (93)

Em indivíduos obesos ou em animais com deficiência total de adiponectina $\left(\mathrm{Ad}^{-1-}\right)$, há menor ativação de AMPK, levando maior estresse oxidativo, perda de processos podais e consequente escape de albumina para o filtrado glomerular.

Além de atuar sobre os podócitos em condições basais (sem co-existência de obesidade, hipertensão ou hiperglicemia), a adiponectina tem papel nefroprotetor em modelos de nefropatia diabética, de redução da massa renal e de depleção específica de podócitos. Em camundongos diabéticos, a deleção de adiponectina exacerba a inflamação, fibrose e hipertrofia renal. Ainda foi visto que a adição de adiponectina em cultura celular de células mesangiais glomerulares atenuam a sinalização do fator nuclear $\kappa \mathrm{B}(\mathrm{NF}-\kappa \mathrm{B})$, um importante regulador da inflamação celular, da proteína alvo da rapamicina em mamíferos (mTOR) e do fator de transformação do crescimento $\beta$ (TGF- $\beta$ ), uma citocina pró-fibrótica, induzida por altas concentrações de glicose (94). 
Esse efeito nefroprotetor sobre a nefropatia diabética também é vista em ratos (95). Em outro estudo, os animais Adipo $^{-/-}$foram submetidos a nefroctomia 5/6 (redução da massa renal) e apresentaram exacerbação de albuminúria, fibrose e infiltração de macrófagos quando comparado aos animais Adipo ${ }^{+/+}$(96). Adicionalmente, um elegante trabalho feito por Rutkowski e coladoradores (97) demonstrou que animais que superexpressavam adiponectina se recuperaram mais rapidamente e exibiram menos fibrose intersticial depois de dano podócito-específico.

Ainda foi observado o papel nefroprotetor da adiponectina sobre os efeitos deletérios da angiotensina II no rim. Particularmente, Fang et al. (82) observaram que a adiponectina, atenua, via adipoR1 (sinalização de AMPK e cAMP-Epac), a ativação da NADPH oxidase e estresse oxidativo induzidos pela angiotensina II em células tubulares renais. Adicionalmente, adiponectina atenuou o aumento na atividade do NF$\kappa \mathrm{B}$ bem como a expressão proteica de fibronectina causada pela estimulação de angiotensina II.

Menos estudados são os efeitos anti-esteatóticos da adiponectina. Porém, Guo e Zhao (98) mostraram que a diminuição de adiponectina plasmática e da expressão de AdipoR1 no rim de ratos diabéticos resulta no aumento de TG renal, que por sua vez, estimula a expressão renal do fator de crescimento de tecido conjuntivo (CTGF) levando a hipertrofia renal e a deterioração da função renal. Ainda, esse aumento dos níveis de TG no rim foi acompanhado de diminuição da fosforilação da AMPK e expressão proteica da ACC.

\subsection{MicroRNAs na fisiopatologia da DRC}

MicroRNAs (miR) são pequenas moléculas de RNA não codificante de $~ 18-$ $24 \mathrm{nt}$, produzidos endogenamente que regulam a expressão gênica póstranscricionalmente. Através do pareamento de base com um RNAm alvo, eles podem regular a estabilidade e tradução do transcrito (99).

Através da regulação da expressão gênica, os microRNAs têm papel importante em muitas atividades fisiológicas tais como ciclo celular, crescimento, proliferação, apoptose e metabolismo, contribuindo para a manutenção da homeostase e desenvolvimento de órgãos (100). No entanto, alterações de fatores intrínsecos (genéticos ou epigenéticos) ou extrínsecos (estímulos ambientais ou estresse) podem 
levar a uma desregulação da expressão e função dos microRNAs e dessa forma alterar o padrão de expressão de certos genes (101).

No rim, os microRNAs têm sido associados com diversos processos fisiológicos e patológicos incluindo a nefropatia diabética, doenças imunes (nefropatia por IgA, nefrite lúpica), doença renal policística e outras (102). A presença de microRNAs no soro e urina sugere potencial uso como biomarcadores precoces para detecção de doenças renais. Adicionalmente, o estudo do papel patogênico dos microRNAs abre as portas para um novo alvo terapêutico durante as doenças renais (103).

Pacientes com diferentes tipos de DRC perdem progressivamente sua função renal e desenvolvem esclerose glomerular e fibrose intersticial. O maior mediador da fibrose renal é o TGF- $\beta$, o qual está associado a alteração de expressão de vários microRNAs $(103,104)$. Na revisão de Chung e Lan (103) é destacado vários estudos que mostraram o papel de microRNAs tais como o miR-29 e miR-192 na fibrose. Particularmente, membros da família miR-29 protegem os rins da fibrose renal pela supressão de deposição de matriz extracelular. Por exemplo, Castoldi et al. (105) observaram redução da expressão do microRNA miR-29a, cujo um dos alvos é a metaloproteinase de matriz-2, em células tubulares no modelo de fibrose induzida por angiotensina II. Fang et al. (106) observaram redução do miR-29c em rins de ratos submetidos à nefrectomia e isso foi associada com maior fibrose intersticial. Além do seu papel na fibrose, o microRNA miR-29a está envolvida na homeostase podocitária (107).

Outros microRNAs estão implicados na fibrose renal tais como o miR-130b e o miR-143. Bai et al. (108) demonstraram que os níveis desses microRNAs estão reduzidos em pacientes com doença renal crônica diabética. Adicionalmente, a inibição do microRNA miR-130b aumenta a expressão de Snail em cultura de células expostas a altas concentrações de glicose. O aumento da expressão de Snail está associado ao aumento da expressão de colágeno IV, que pode contribuir para a fibrose túbulo intersticial na doença renal diabética. Müller-Deile et al. (109) ainda mostrou que o microRNA miR-143 é induzido por TGF- $\beta$ em podócitos e que ele funciona como um mediador na comunicação parácrina e autócrina entre podócitos e células endoteliais e pode alterar a expressão de proteínas do glicocálice glomerular.

Sabendo da contribuição dos microRNAs no desenvolvimento de características patológicas no rim, faz-se relevante o estudo de microRNAs no rim na obesidade bem como se eles são influenciados pela expressão de adiponectina. 


\section{CONCLUSÃO}

No nosso estudo, observamos que animais WT e AdipoKO respondem de maneira quase similar a HFD (vide tabela 7). No entanto, animais deficientes em adiponectina (independente da dieta que receberam) apresentaram maior peso renal, aumento da expressão gênica de Fabp4, pior progressão da albuminúria, menor expressão gênica de Cptla (o que poderia implicar em menor oxidação de ácidos graxos) e aumento do miR-130b. Mais importante, a falta de adiponectina somado a obesidade promove diminuição na expressão proteica de nefrina e exacerbação da albuminúria. Curiosamente, a falta de adiponectina não parece levar a piora da esteatose renal provocados pela HFD. Considerados em conjunto, esses resultados indicam que a falta de adiponectina influencia na diminuição da função renal (caracterizada pela albuminúria) mas não é significativa no acúmulo de lipídeos observados no rim obeso. 


\section{REFERÊNCIAS $^{1}$}

1. WHO. Obesity and overweight, WHO fact sheet 311 [Internet]. World Health Organization Website. 2018. Available from: http://www.who.int/newsroom/fact-sheets/detail/obesity-and-overweight

2. Diretrizes Brasileiras de obesidade/ABESO. Diretrizes brasileiras de obesidade 2016/ABESO. 4.ed - São Paulo, SP. 2016;1-188.

3. WHO. Obesity: Preventing and Managing the Global Epidemic. Report of a WHO Consultation. WHO Technical Report Series no. 894. WHO. 2000.

4. Bahia L, Araújo DV. Impacto econômico da obesidade no Brasil. Rev Hosp Univ Pedro Ernesto. 2014;13(1).

5. Felizardo RJF. Obesity in kidney disease: A heavyweight opponent. World J Nephrol. 2014;3(3):50.

6. Akram DS, Astrup A V., Atinmo T, Boissin JL, Bray GA, Carroll KK, et al. Obesity: Preventing and managing the global epidemic. World Health Organization - Technical Report Series. 2000.

7. Mancini MC. Obesidade e Doenças Associadas. In: Tratado de Obesidade. Segunda Ed. 2015.

8. Redon J, Lurbe E. The kidney in obesity. Curr Hypertens Rep. 2015;17(6):555.

9. Kambham N, Markowitz GS, Valeri AM, Lin J, D'Agati VD. Obesity-related glomerulopathy: An emerging epidemic. Kidney Int. 2001;59(4):1498-509.

10. Nasri H, Amiri M. World kidney day 2017 with the theme of kidney disease and obesity. 2017;2(1):1-2.

11. Câmara NOS, Iseki K, Kramer H, Liu ZH, Sharma K. Kidney disease and obesity: Epidemiology, mechanisms and treatment. Vol. 13, Nature Reviews Nephrology. 2017. p. 181-90.

12. Boron WF, Boulpaep EL. Medical Physiology A Cellular and Molecular Approach. Vol. 53, Journal of Chemical Information and Modeling. 2013. 1689$1699 \mathrm{p}$.

13. Leeuwis JW, Nguyen TQ, Dendooven A, Kok RJ, Goldschmeding R. Targeting podocyte-associated diseases. Vol. 62, Advanced Drug Delivery Reviews. 2010. p. 1325-36.

14. Patrakka J, Tryggvason K. Molecular make-up of the glomerular filtration barrier. Biochem Biophys Res Commun. 2010;396(1):164-9.

15. Eckardt KU, Coresh J, Devuyst O, Johnson RJ, Köttgen A, Levey AS, et al. Evolving importance of kidney disease: From subspecialty to global health burden. Vol. 382, The Lancet. 2013. p. 158-69.

16. Briffa JF, McAinch AJ, Poronnik P, Hryciw DH. Adipokines as a link between obesity and chronic kidney disease. Am J Physiol Ren Physiol. 2013;305(12):F1629-36.

17. Marshall CB. Rethinking glomerular basement membrane thickening in diabetic nephropathy: adaptive or pathogenic? Am J Physiol Physiol. 2016;311(5):F83143.

18. Alghamdi TA, Majumder S, Thieme K, Batchu SN, White KE, Liu Y, et al. Janus Kinase 2 Regulates Transcription Factor EB Expression and Autophagy

1 De acordo com: International Committee of Medical Journal Editors. Uniforme requeriments for manuscripts submitted to Biomedical Journal: sample references. 2003 [cited 2019 April 15]. Disponível em: https://www.nlm.nih.gov/bsd/uniform_requirements.html 
Completion in Glomerular Podocytes. J Am Soc Nephrol [Internet]. 2017;28(9):2641-53. Available from: http://www.jasn.org/lookup/doi/10.1681/ASN.2016111208

19. Mundel P. Podocytes and the quest for precision medicines for kidney diseases. Vol. 469, Pflugers Archiv European Journal of Physiology. 2017. p. 1029-37.

20. Mundel P, Reiser J. Proteinuria: an enzymatic disease of the podocyte? Kidney Int [Internet]. 2010 Apr [cited 2019 Feb 13];77(7):571-80. Available from: http://www.ncbi.nlm.nih.gov/pubmed/19924101

21. Shankland SJ. The podocyte's response to injury: role in proteinuria and glomerulosclerosis. Kidney Int [Internet]. 2006;69(12):2131-47. Available from: http://www.ncbi.nlm.nih.gov/pubmed/16688120

22. Miner JH. Focusing on the glomerular slit diaphragm: Podocin enters the picture. Vol. 160, American Journal of Pathology. 2002. p. 3-5.

23. Wiggins JE. Podocyte Hypertrophy, "Adaptation," and "Decompensation" Associated with Glomerular Enlargement and Glomerulosclerosis in the Aging Rat: Prevention by Calorie Restriction. J Am Soc Nephrol. 2005;16(10):2953-66.

24. Kaissling B, LeHir M, Kriz W. Renal epithelial injury and fibrosis. Vol. 1832, Biochimica et Biophysica Acta - Molecular Basis of Disease. 2013. p. 931-9.

25. Mundel P. Podocytes and the quest for precision medicines for kidney diseases. Pflugers Arch Eur J Physiol. Pflügers Archiv - European Journal of Physiology; 2017;469(7-8):1029-37.

26. Chapter 1: Definition and classification of CKD. Kidney Int Suppl [Internet]. Elsevier; 2013 Jan 1 [cited 2019 Feb 13];3(1):19-62. Available from: https://linkinghub.elsevier.com/retrieve/pii/S2157171615311011

27. Hewitson TD. Renal tubulointerstitial fibrosis: common but never simple. AJP Ren Physiol [Internet]. 2009;296(6):F1239-44. Available from: http://ajprenal.physiology.org/cgi/doi/10.1152/ajprenal.90521.2008

28. López-Novoa JM, Martínez-Salgado C, Rodríguez-Peña AB, Hernández FJL. Common pathophysiological mechanisms of chronic kidney disease: Therapeutic perspectives. Pharmacol Ther [Internet]. Elsevier Inc.; 2010;128(1):61-81. Available from: http://dx.doi.org/10.1016/j.pharmthera.2010.05.006

29. Nogueira A, Pires MJ, Oliveira PA. Pathophysiological mechanisms of renal fibrosis: A review of animal models and therapeutic strategies. Vol. 31, In Vivo. 2017. p. 1-22.

30. Webster AC, Nagler E V, Morton RL, Masson P. Seminar Chronic kidney disease [Internet]. Vol. 389, The Lancet. 2017. Available from: http://dx.doi.org/10.1016/

31. National Kidney Foundation. K/DOQI clinical practice guidelines for chronic kidney disease: evaluation, classification, and stratification. Am J Kidney Dis [Internet]. 2002 Feb [cited 2019 Feb 13];39(2 Suppl 1):S1-266. Available from: http://www.ncbi.nlm.nih.gov/pubmed/11904577

32. Mount P, Davies M, Choy S-W, Cook N, Power D. Obesity-Related Chronic Kidney Disease-The Role of Lipid Metabolism. Metabolites [Internet]. 2015 [cited 2016 Sep 2];5(4):720-32. Available from: http://www.ncbi.nlm.nih.gov/pubmed/26690487

33. Wickman C, Kramer H. Obesity and kidney disease: potential mechanisms. Semin Nephrol [Internet]. 2013 Jan [cited 2016 Sep 28];33(1):14-22. Available from: http://www.ncbi.nlm.nih.gov/pubmed/23374890

34. De Vries APJ, Ruggenenti P, Ruan XZ, Praga M, Cruzado JM, Bajema IM, et al. Fatty kidney: Emerging role of ectopic lipid in obesity-related renal disease. Vol. 2, The Lancet Diabetes and Endocrinology. 2014. p. 417-26. 
35. Weisinger JR, Kempson RL, Eldridge FL, Swenson RS. The nephrotic syndrome: a complication of massive obesity. Ann Intern Med. 1974;81(4):4407.

36. Briffa JF, McAinch AJ, Poronnik P, Hryciw DH. Adipokines as a link between obesity and chronic kidney disease. Am J Physiol Physiol. 2013;305(12):F162936.

37. D’Agati VD, Kaskel FJ, Falk RJ. Focal Segmental Glomerulosclerosis. N Engl J Med [Internet]. 2011 Dec 22 [cited 2019 Feb 13];365(25):2398-411. Available from: http://www.ncbi.nlm.nih.gov/pubmed/22187987

38. D'Agati VD, Chagnac A, De Vries APJ, Levi M, Porrini E, Herman-Edelstein M, et al. Obesity-related glomerulopathy: Clinical and pathologic characteristics and pathogenesis. Vol. 12, Nature Reviews Nephrology. 2016. p. 453-71.

39. Larkin BP, Glastras SJ, Chen H, Pollock CA, Saad S. DNA methylation and the potential role of demethylating agents in prevention of progressive chronic kidney disease. FASEB J. 2018;32(10):5215-26.

40. Hoy WE, Douglas-Denton RN, Hughson MD, Cass A, Johnson K, Bertram JF. A stereological study of glomerular number and volume: Preliminary findings in a multiracial study of kidneys at autopsy. Kidney Int. 2003;63:S31-7.

41. Wu Y, Liu Z, Xiang Z, Zeng C, Chen Z, Ma X, et al. Obesity-related glomerulopathy: Insights from gene expression profiles of the glomeruli derived from renal biopsy samples. Endocrinology. 2006;147(1):44-50.

42. Jiang T, Wang Z, Proctor G, Moskowitz S, Liebman SE, Rogers T, et al. Dietinduced obesity in C57BL/6J mice causes increased renal lipid accumulation and glomerulosclerosis via a sterol regulatory element-binding protein-1c-dependent pathway. J Biol Chem. 2005;280(37):32317-25.

43. Min HS, Kim JE, Lee MH, Song HK, Lee MJ, Lee JE, et al. Effects of Toll-like receptor antagonist 4,5-dihydro-3-phenyl-5-isoxasole acetic acid on the progression of kidney disease in mice on a high-fat diet. Kidney Res Clin Pract [Internet]. 2014 Mar [cited 2016 Sep 13];33(1):33-44. Available from: http://www.ncbi.nlm.nih.gov/pubmed/26877948

44. Deji N, Kume S, Araki S, Soumura M, Sugimoto T, Isshiki K, et al. Structural and functional changes in the kidneys of high-fat diet-induced obese mice. Am J Physiol Renal Physiol [Internet]. 2009;296(1):118-26. Available from: http://www.ncbi.nlm.nih.gov/pubmed/18971213

45. Fang Q, Deng L, Wang L, Zhang Y, Weng Q, Yin H, et al. Inhibition of MAPKs/NF- $\kappa \mathrm{B}$-dependent inflammation by a novel chalcone protects kidney from high fat diet-induced injuries in mice. J Pharmacol Exp Ther [Internet]. 2015; Available from: http://www.ncbi.nlm.nih.gov/pubmed/26354992

46. Gai Z, Wang T, Visentin M, Kullak-Ublick G, Fu X, Wang Z. Lipid Accumulation and Chronic Kidney Disease. Nutrients [Internet]. 2019;11(4):722. Available from: https://www.mdpi.com/2072-6643/11/4/722

47. Yamamoto T, Takabatake Y, Takahashi A, Kimura T, Namba T, Matsuda J, et al. High-Fat Diet-Induced Lysosomal Dysfunction and Impaired Autophagic Flux Contribute to Lipotoxicity in the Kidney. J Am Soc Nephrol [Internet]. 2016;1534-51. Available from: http://www.jasn.org/cgi/doi/10.1681/ASN.2016070731

48. Bobulescu IA. Renal lipid metabolism and lipotoxicity. Vol. 19, Current Opinion in Nephrology and Hypertension. 2010. p. 393-402.

49. Yang P, Xiao Y, Luo X, Zhao Y, Zhao L, Wang Y, et al. Inflammatory stress promotes the development of obesity-related chronic kidney disease via CD36 in mice. J Lipid Res [Internet]. 2017;58(7):1417-27. Available from: 
http://www.jlr.org/lookup/doi/10.1194/jlr.M076216

50. Postic C, Girard J. Contribution of de novo fatty acid synthesis to hepatic steatosis and insulin resistance: Lessons from genetically engineered mice. Vol. 118, Journal of Clinical Investigation. 2008. p. 829-38.

51. Kume S, Uzu T, Araki S, Sugimoto T, Isshiki K, Chin-Kanasaki M, et al. Role of altered renal lipid metabolism in the development of renal injury induced by a high-fat diet. J Am Soc Nephrol. 2007;18(10):2715-23.

52. Declèves A-E, Zolkipli Z, Satriano J, Wang L, Nakayama T, Rogac M, et al. Regulation of lipid accumulation by AMK-activated kinase in high fat dietinduced kidney injury. Kidney Int [Internet]. 2014;85:611-23. Available from: http://www.ncbi.nlm.nih.gov/pubmed/24304883

53. Tanaka Y, Kume S, Araki S, Isshiki K, Chin-Kanasaki M, Sakaguchi M, et al. Fenofibrate, a PPAR $\alpha$ agonist, has renoprotective effects in mice by enhancing renal lipolysis. Kidney Int [Internet]. Elsevier Masson SAS; 2011;79(8):871-82. Available from: http://www.ncbi.nlm.nih.gov/pubmed/21270762

54. Gotoh K, Masaki T, Chiba S, Ando H, Fujiwara K, Shimasaki T, et al. Effects of hydrophilic statins on renal tubular lipid accumulation in diet-induced obese mice. Obes Res Clin Pract. 2013;7(5).

55. Kim D, Lee JE, Jung YJ, Lee AS, Lee S, Park SK, et al. Metformin decreases high-fat diet-induced renal injury by regulating the expression of adipokines and the renal AMP-activated protein kinase/acetyl-CoA carboxylase pathway in mice. Int J Mol Med. 2013;32(6):1293-302.

56. Declèves A-E, Mathew A V, Cunard R, Sharma K. AMPK mediates the initiation of kidney disease induced by a high-fat diet. J Am Soc Nephrol [Internet]. 2011 Oct [cited 2016 Sep 28];22(10):1846-55. Available from: http://www.ncbi.nlm.nih.gov/pubmed/21921143

57. Wang XXX, Jiang T, Shen Y, Santamaria H, Solis N, Arbeeny C, et al. Vitamin $\mathrm{D}$ receptor agonist doxercalciferol modulates dietary fat-induced renal disease and renal lipid metabolism. Am J Physiol Physiol. 2011;300(3):F801-10.

58. Wang XX, Edelstein MH, Gafter U, Qiu L, Luo Y, Dobrinskikh E, et al. G Protein-Coupled Bile Acid Receptor TGR5 Activation Inhibits Kidney Disease in Obesity and Diabetes. J Am Soc Nephrol. 2015;27(5):1362-78.

59. Feng B, Meng R, Huang B, Bi Y, Shen S, Zhu D. Silymarin protects against renal injury through normalization of lipid metabolism and mitochondrial biogenesis in high fat-fed mice. Free Radic Biol Med. 2017;110:240-9.

60. Wang XX, Jiang T, Shen Y, Adorini L, Pruzanski M, Gonzalez FJ, et al. The farnesoid $X$ receptor modulates renal lipid metabolism and diet-induced renal inflammation, fibrosis, and proteinuria. Am J Physiol Physiol. 2009;297(6):F1587-96.

61. Chen W, Zhang Q, Cheng S, Huang J, Diao G, Han J. Atgl gene deletion predisposes to proximal tubule damage by impairing the fatty acid metabolism. Biochem Biophys Res Commun. 2017;487(1):160-6.

62. Chen W, Jiang Y, Han J, Hu J, He T, Yan T, et al. Atgl deficiency induces podocyte apoptosis and leads to glomerular filtration barrier damage. FEBS J. 2017;284(7):1070-81.

63. Bobulescu IA, Lotan Y, Zhang J, Rosenthal TR, Rogers JT, Adams-Huet B, et al. Triglycerides in the human kidney cortex: Relationship with body size. PLoS One. 2014;9(8).

64. Herman-Edelstein M, Scherzer P, Tobar A, Levi M, Gafter U. Altered renal lipid metabolism and renal lipid accumulation in human diabetic nephropathy. J Lipid Res [Internet]. 2014;55(3):561-72. Available from: 
http://www.ncbi.nlm.nih.gov/pubmed/24371263

65. Kang HM, Ahn SH, Choi P, Ko YA, Han SH, Chinga F, et al. Defective fatty acid oxidation in renal tubular epithelial cells has a key role in kidney fibrosis development. Nat Med. 2015;21(1):37-46.

66. Scerbo D, Son N-H, Sirwi A, Zeng L, Sas KM, Cifarelli V, et al. Kidney triglyceride accumulation in the fasted mouse is dependent upon serum free fatty acids. J Lipid Res. 2017;58(6):1132-42.

67. Unger RH, Orci L. Lipotoxic diseases of nonadipose tissues in obesity. Int $\mathbf{J}$ Obes. 2000;24:S28-32.

68. Scherer PE, Williams S, Fogliano M, Baldini G, Lodish HF. A novel serum protein similar to $\mathrm{C} 1 \mathrm{q}$, produced exclusively in adipocytes. $\mathrm{J}$ Biol Chem. 1995;270(45):26746-9.

69. Yamauchi T, Kamon J, Waki H, Terauchi Y, Kubota N, Hara K, et al. The fatderived hormone adiponectin reverses insulin resistance associated with both lipoatrophy and obesity. Nat Med. 2001;7(8):941-6.

70. Ronti T, Lupattelli G, Mannarino E. The endocrine function of adipose tissue: An update. Vol. 64, Clinical Endocrinology. 2006. p. 355-65.

71. J. Hickman I, P. Whitehead J. Structure, Signalling and Physiologic Role of Adiponectin-Dietary and Exercise- Related Variations. Curr Med Chem. 2012;19(32):5427-43.

72. Berner HS, Lyngstadaas SP, Spahr A, Monjo M, Thommesen L, Drevon CA, et al. Adiponectin and its receptors are expressed in bone-forming cells. Bone. 2004;35(4):842-9.

73. Kaser S, Maschen A, Cayon A, Kaser A, Crespo J, Pons-Romero F, et al. Adiponectin and its receptors in non-alcoholic steatohepatitis. Gut. 2005;54(1):117-21.

74. Delaigle AM, Jonas JC, Bauche IB, Cornu O, Brichard SM. Induction of adiponectin in skeletal muscle by inflammatory cytokines: In vivo and in vitro studies. Endocrinology. 2004;145(12):5589-97.

75. Piñeiro R, Iglesias MJ, Gallego R, Raghay K, Eiras S, Rubio J, et al. Adiponectin is synthesized and secreted by human and murine cardiomyocytes. FEBS Lett. 2005;579(23):5163-9.

76. Perri A, Vizza D, Lofaro D, Gigliotti P, Leone F, Brunelli E, et al. Adiponectin is expressed and secreted by renal tubular epithelial cells. J Nephrol. 2013;26(6):1049-54.

77. Crawford LJA, Peake R, Price S, Morris TCM, Irvine AE. Adiponectin is produced by lymphocytes and is a negative regulator of granulopoiesis. J Leukoc Biol. 2010;88(4):807-11.

78. Miller M, Cho JY, Pham A, Ramsdell J, Broide DH. Adiponectin and Functional Adiponectin Receptor 1 Are Expressed by Airway Epithelial Cells in Chronic Obstructive Pulmonary Disease. J Immunol. 2014;182(1):684-91.

79. Katsiougiannis S, Kapsogeorgou EK, Manoussakis MN, Skopouli FN. Salivary gland epithelial cells: A new source of the immunoregulatory hormone adiponectin. Arthritis Rheum. 2006;54(7):2295-9.

80. Denzel MS, Scimia MC, Zumstein PM, Walsh K, Ruiz-Lozano P, Ranscht B. Tcadherin is critical for adiponectin-mediated cardioprotection in mice. $\mathrm{J}$ Clin Invest. 2010;120(12):4342-52.

81. Garitaonandia I, Smith JL, Kupchak BR, Lyons TJ. Adiponectin identified as an agonist for PAQR3/RKTG using a yeast-based assay system. J Recept Signal Transduct. 2009;29(1):67-73.

82. Fang F, Liu GC, Kim C, Yassa R, Zhou J, Scholey JW. Adiponectin attenuates 
angiotensin II-induced oxidative stress in renal tubular cells through AMPK and cAMP-Epac signal transduction pathways. Am J Physiol Ren Physiol [Internet]. 2013;304(11):F1366-74. http://www.ncbi.nlm.nih.gov/pubmed/23535586

Available from:

83. Sharma K, RamachandraRao S, Qiu G, Usui HK, Zhu Y, Dunn SR, et al. Adiponectin regulates albuminuria and podocyte function in mice. J Clin Invest. 2008;118(5):1645-56.

84. Hardie DG, Scott JW, Pan DA, Hudson ER. Management of cellular energy by the AMP-activated protein kinase system. Vol. 546, FEBS Letters. 2003. p. 11320.

85. Mao X, Hong J, Dong L. The Adiponectin Signaling Pathway as a Novel Pharmacological Target. Mini-Reviews Med Chem. 2006;6(12):1331-40.

86. Zhou G, Myers R, Li Y, Chen Y, Shen X, Fenyk-Melody J, et al. Role of AMPactivated protein kinase in mechanism of metformin action. $\mathrm{J}$ Clin Invest. 2001;108(8):1167-74.

87. Lee WJ, Kim M, Park HS, Kim HS, Jeon MJ, Oh KS, et al. AMPK activation increases fatty acid oxidation in skeletal muscle by activating PPAR $\alpha$ and PGC1. Biochem Biophys Res Commun. 2006;340(1):291-5.

88. Sweiss N, Sharma K. Adiponectin effects on the kidney. In: Best Practice and Research: Clinical Endocrinology and Metabolism. 2014. p. 71-9.

89. Tsioufis C, Dimitriadis K, Chatzis D, Vasiliadou C, Tousoulis D, Papademetriou $\mathrm{V}$, et al. Relation of microalbuminuria to adiponectin and augmented C-reactive protein levels in men with essential hypertension. Am J Cardiol. 2005;96(7):94651.

90. Yano Y, Hoshide S, Ishikawa J, Hashimoto T, Eguchi K, Shimada K, et al. Differential impacts of adiponectin on low-grade albuminuria between obese and nonobese persons without diabetes. J Clin Hypertens (Greenwich). 2007;9(10):775-82.

91. Arita Y, Kihara S, Ouchi N, Takahashi M, Maeda K, Miyagawa JI, et al. Paradoxical decrease of an adipose-specific protein, adiponectin, in obesity. Biochem Biophys Res Commun. 1999;257(1):79-83.

92. Yang J, Lin S-C, Chen G, He L, Hu Z, Chan L, et al. Adiponectin Promotes Monocyte-to-Fibroblast Transition in Renal Fibrosis. J Am Soc Nephrol. 2013;24(10):1644-59.

93. Ahima RS. Linking adiponectin to proteinuria. Vol. 118, Journal of Clinical Investigation. 2008. p. 1619-22.

94. Fang F, Bae EH, Hu A, Liu GC, Zhou X, Williams V, et al. Deletion of the gene for adiponectin accelerates diabetic nephropathy in the Ins2 +/C96Y mouse. Diabetologia. 2015;58(7):1668-78.

95. Nakamaki S, Satoh H, Kudoh A, Hayashi Y, Hirai H, Watanabe T. Adiponectin reduces proteinuria in streptozotocin-induced diabetic Wistar rats. Exp Biol Med (Maywood) [Internet]. 2011;236(5):614-20. Available from: http://www.ncbi.nlm.nih.gov/pubmed/21521713

96. Ohashi K, Iwatani H, Kihara S, Nakagawa Y, Komura N, Fujita K, et al. Exacerbation of albuminuria and renal fibrosis in subtotal renal ablation model of adiponectin-knockout mice. Arterioscler Thromb Vasc Biol. 2007;27(9):1910-7.

97. Rutkowski JM, Wang ZV, Park ASD, Zhang J, Zhang D, Hu MC, et al. Adiponectin promotes functional recovery After podocyte ablation. J Am Soc Nephrol. 2013;24(2).

98. Guo Z, Zhao Z. Effect of N-acetylcysteine on plasma adiponectin and renal adiponectin receptors in streptozotocin-induced diabetic rats. Eur J Pharmacol. 
2007;558(1-3):208-13.

99. Oghbaei H, Asl NA, Sheikhzadeh F, Alipour MR, Khamaneh AM. The Effect of regular moderate exercise on miRNA-192 expression changes in kidney of streptozotocin-induced diabetic male rats. Adv Pharm Bull. 2015;5(1):127-32.

100. Schena FP, Serino G, Sallustio F. MicroRNAs in kidney diseases: New promising biomarkers for diagnosis and monitoring. Nephrol Dial Transplant. 2014;29(4):755-63.

101. Rottiers V, Najafi-Shoushtari SH, Kristo F, Gurumurthy S, Zhong L, Li Y, et al. Micrornas in metabolism and metabolic diseases. Cold Spring Harb Symp Quant Biol. 2011;76(4):225-33.

102. Trionfini P, Benigni A, Remuzzi G. MicroRNAs in kidney physiology and disease. Nat Rev Nephrol [Internet]. Nature Publishing Group; 2014;11(1):2333. Available

from: http://dx.doi.org/10.1038/nrneph.2014.202ไnhttp://www.nature.com/doifinder/10. 1038/nrneph.2014.202

103. Chung ACK, Lan HY. MicroRNAs in renal fibrosis. Vol. 6, Frontiers in Physiology. 2015.

104. Deshpande S, Abdollahi M, Wang M, Lanting L, Kato M, Natarajan R. Reduced Autophagy by a microRNA-mediated Signaling Cascade in Diabetes-induced Renal Glomerular Hypertrophy. Sci Rep. 2018;8(1).

105. Castoldi G, di Gioia C, Giollo F, Carletti R, Bombardi C, Antoniotti M, et al. Different regulation of miR-29a-3p in glomeruli and tubules in an experimental model of angiotensin II-dependent hypertension: Potential role in renal fibrosis. Clin Exp Pharmacol Physiol. 2016;43(3):335-42.

106. Fang Y, Yu X, Liu Y, Kriegel AJ, Heng Y, Xu X, et al. miR-29c is downregulated in renal interstitial fibrosis in humans and rats and restored by HIF- $\alpha$ activation. Am J Physiol Physiol. 2013;304(10):F1274-82.

107. Lin C-L, Lee P-H, Hsu Y-C, Lei C-C, Ko J-Y, Chuang P-C, et al. MicroRNA29a Promotion of Nephrin Acetylation Ameliorates Hyperglycemia-Induced Podocyte Dysfunction. J Am Soc Nephrol. 2014;25(8):1698-709.

108. Bai X, Geng J, Zhou Z, Tian J, Li X. MicroRNA-130b improves renal tubulointerstitial fibrosis via repression of Snail-induced epithelial-mesenchymal transition in diabetic nephropathy. Sci Rep. 2016;6.

109. Müller-Deile J, Gellrich F, Schenk H, Schroder P, Nyström J, Lorenzen J, et al. Overexpression of TGF- $\beta$ Inducible microRNA-143 in Zebrafish Leads to Impairment of the Glomerular Filtration Barrier by Targeting Proteoglycans. Cell Physiol Biochem. 2016;40(5):819-30.

110. Ke M, Cabrero A, Saha PK, Kojima H, Li L, Chang BHJ, et al. Increased $\beta$ oxidation but no insulin resistance or glucose intolerance in mice lacking adiponectin. J Biol Chem. 2002;277(38):34658-61.

111. Frias F de T, Rocha KCE, de Mendonça M, Murata GM, Araujo HN, de Sousa LGO, et al. Fenofibrate reverses changes induced by high-fat diet on metabolism in mice muscle and visceral adipocytes. J Cell Physiol. 2018;233(4):3515-28.

112. Bowe JE, Franklin ZJ, Hauge-Evans AC, King AJ, Persaud SJ, Jones PM. METABOLIC PHENOTYPING GUIDELINES: Assessing glucose homeostasis in rodent models. J Endocrinol. 2014;222(3):G13-25.

113. Amaral MEC, Oliveira HCF, Carneiro EM, Delghingaro-Augusto V, Vieira EC, Berti JA, et al. Plasma glucose regulation and insulin secretion in hypertriglyceridemic mice. Horm Metab Res. 2002;34(1):21-6.

114. Geloneze B, Tambascia MA. Avaliação laboratorial e diagnóstico da resistência insulínica. Arq Bras Endocrinol Metabol. 2006;50(2):208-15. 
115. Kenneth J. Livak* and Thomas D. Schmittgen $\dagger 1, *$ Applied. Analysis of Relative Gene Expression Data Using Real- Time Quantitative PCR and the $2 \geqslant-\Delta \Delta \mathrm{CT}$ Method. METHODS. 2001;25:402-8.

116. Majumder S, Thieme K, Batchu SN, Alghamdi TA, Bowskill BB, Golam Kabir $\mathrm{M}$, et al. Shifts in podocyte histone H3K27me3 regulate mouse and human glomerular disease. J Clin Invest. 2018;128(1):483-99.

117. Towbin H, Staehelin T, Gordon J. Electrophoretic transfer of proteins from polyacrylamide gels to nitrocellulose sheets: procedure and some applications. 1979. Biotechnology [Internet]. 1992;24:145-9. Available from: http://www.ncbi.nlm.nih.gov/pubmed/1422008

118. Corrales P, Izquierdo-Lahuerta A, Medina-Gómez G. Maintenance of Kidney Metabolic Homeostasis by PPAR Gamma. Int J Mol Sci. 2018;19(7):2063.

119. Supruniuk E, Miklosz A, Chabowski A. The implication of PGC-1 $\alpha$ on fatty acid transport across plasma and mitochondrial membranes in the insulin sensitive tissues. Vol. 8, Frontiers in Physiology. 2017.

120. D'Agati VD, Chagnac A, de Vries APJ, Levi M, Porrini E, Herman-Edelstein M, et al. Obesity-related glomerulopathy: clinical and pathologic characteristics and pathogenesis. Nat Rev Nephrol [Internet]. Nature Publishing Group; 2016;12(8):453-71. Available from: http://www.ncbi.nlm.nih.gov/pubmed/27263398

121. Coimbra TM, Janssen U, Gröne HJ, Ostendorf T, Kunter U, Schmidt H, et al. Early events leading to renal injury in obese Zucker (fatty) rats with type II diabetes. Kidney Int. 2000;57(1):167-82.

122. Böttinger EP, Bitzer M. TGF- $\beta$ signaling in renal disease. Vol. 13, Journal of the American Society of Nephrology. 2002. p. 2600-10.

123. Genovese F, Manresa AA, Leeming DJ, Karsdal MA, Boor P. The extracellular matrix in the kidney: A source of novel non-invasive biomarkers of kidney fibrosis? Vol. 7, Fibrogenesis and Tissue Repair. 2014.

124. Koya D, Kanasaki K. Biology of obesity: Lessons from animal models of obesity. Vol. 2011, Journal of Biomedicine and Biotechnology. 2011.

125. Glastras SJ, Chen H, Teh R, McGrath RT, Chen J, Pollock CA, et al. Mouse Models of Diabetes, Obesity and Related Kidney Disease. PLoS One [Internet]. 2016;11(8):e0162131. Available from: http://dx.plos.org/10.1371/journal.pone.0162131

126. Wicks SE, Nguyen TT, Breaux C, Kruger C, Stadler K. Diet-induced obesity and kidney disease - In search of a susceptible mouse model. Biochimie. 2016;124:65-73.

127. Jiang T, Wang Z, Proctor G, Moskowitz S, Liebman SE, Rogers T, et al. Dietinduced Obesity in C57BL/6J Mice Causes Increased Renal Lipid Accumulation and Glomerulosclerosis via a Sterol Regulatory Element-binding Protein-1cdependent Pathway. J Biol Chem [Internet]. American Society for Biochemistry and Molecular Biology; 2005 Sep 16 [cited 2016 Sep 13];280(37):32317-25. Available from: http://www.jbc.org/cgi/doi/10.1074/jbc.M500801200

128. Declèves A-E, Mathew A V., Cunard R, Sharma K. AMPK Mediates the Initiation of Kidney Disease Induced by a High-Fat Diet. J Am Soc Nephrol. 2011;22(10):1846-55.

129. Szeto HH, Liu S, Soong Y, Alam N, Prusky GT, Seshan S V. Protection of mitochondria prevents high fat diet-induced glomerulopathy and proximal tubular injury. Kidney Int [Internet]. 2016; Available from: http://dx.doi.org/10.1016/nhttp://www.kidneyinternational.org/article/S0085253816302952/fulltext 
130. Glastras SJ, Chen H, Teh R, McGrath RT, Chen J, Pollock CA, et al. Mouse models of diabetes, obesity and related kidney disease. PLoS One. 2016;11(8).

131. Dissard R, Klein J, Caubet C, Breuil B, Siwy J, Hoffman J, et al. Long Term Metabolic Syndrome Induced by a High Fat High Fructose Diet Leads to Minimal Renal Injury in C57BL/6 Mice. PLoS One. 2013;8(10).

132. Meyvis K, Verrijken A, Wouters K, Van Gaal L. Plasma adiponectin level is inversely correlated with albuminuria in overweight and obese nondiabetic individuals. Metabolism. 2013;62(11):1570-6.

133. Choi M-S, Kim Y-J, Kwon E-Y, Ryoo JY, Kim SR, Jung UJ. High-fat diet decreases energy expenditure and expression of genes controlling lipid metabolism, mitochondrial function and skeletal system development in the adipose tissue, along with increased expression of extracellular matrix remodelling- and inflammation-related genes. Br J Nutr [Internet]. 2015 Mar 6 [cited 2019 Apr 4];113(6):867-77. Available from: http://www.ncbi.nlm.nih.gov/pubmed/25744306

134. Santos EW, Oliveira DC de, Hastreiter A, Beltran JS de O, Rogero MM, Fock RA, et al. High-fat diet or low-protein diet changes peritoneal macrophages function in mice. Nutr Rev Soc Bras Aliment Nutr [Internet]. 2016;41:1-9. Available from: https://nutrirejournal.biomedcentral.com/articles/10.1186/s41110-016-0006-X

135. Fukuda A, Chowdhury MA, Venkatareddy MP, Wang SQ, Nishizono R, Suzuki T, et al. Growth-Dependent Podocyte Failure Causes Glomerulosclerosis. J Am Soc Nephrol. 2012;23(8):1351-63.

136. Declèves A-E, Zolkipli Z, Satriano J, Wang L, Nakayama T, Rogac M, et al. Regulation of lipid accumulation by AMP-activated kinase [corrected] in high fat diet-induced kidney injury. Kidney Int [Internet]. NIH Public Access; 2014 Mar [cited 2016 Sep 13];85(3):611-23. Available from: http://www.ncbi.nlm.nih.gov/pubmed/24304883

137. Kumada M, Kihara S, Ouchi N, Kobayashi H, Okamoto Y, Ohashi K, et al. Adiponectin Specifically Increased Tissue Inhibitor of Metalloproteinase-1 Through Interleukin-10 Expression in Human Macrophages. Circulation. 2004;109(17):2046-9.

138. Geiszt M, Kopp JB, Varnai P, Leto TL. Identification of Renox, an NAD(P)H oxidase in kidney. Proc Natl Acad Sci. 2002;97(14):8010-4.

139. Gorin Y, Block K, Hernandez J, Bhandari B, Wagner B, Barnes JL, et al. Nox4 $\mathrm{NAD}(\mathrm{P}) \mathrm{H}$ oxidase mediates hypertrophy and fibronectin expression in the diabetic kidney. J Biol Chem. 2005;280(47):39616-26.

140. Michaud J-LR, Kennedy CRJ. The podocyte in health and disease: insights from the mouse. Clin Sci. 2007;112(6):325-35.

141. Benzing T. Signaling at the slit diaphragm. Vol. 15, Journal of the American Society of Nephrology. 2004. p. 1382-91.

142. Putaala $\mathrm{H}$. The murine nephrin gene is specifically expressed in kidney, brain and pancreas: inactivation of the gene leads to massive proteinuria and neonatal death. Hum Mol Genet. 2002;10(1):1-8.

143. Roselli S, Heidet L, Sich M, Henger A, Kretzler M, Gubler M-C, et al. Early Glomerular Filtration Defect and Severe Renal Disease in Podocin-Deficient Mice. Mol Cell Biol. 2003;24(2):550-60.

144. Ghayur A, Liu L, Kolb M, Chawla A, Lambe S, Kapoor A, et al. Adenovirusmediated gene transfer of TGF- $\beta 1$ to the renal glomeruli leads to proteinuria. Am J Pathol. 2012;180(3):940-51.

145. Ziyadeh FN. Mediators of Diabetic Renal Disease: The Case for TGF- as the 
Major Mediator. J Am Soc Nephrol. 2004;15(90010):55S-57.

146. Schaefer L, Han X, August C, Matzkies F, Lorenz T, Schaefer RM. Differential regulation of glomerular gelatinase B (MMP-9) and tissue inhibitor of metalloproteinase-1 (TIMP-1) in obese Zucker rats. Diabetologia. 1997;40(9):1035-43.

147. Shi S, Yu L, Chiu C, Sun Y, Chen J, Khitrov G, et al. Podocyte-Selective Deletion of Dicer Induces Proteinuria and Glomerulosclerosis. J Am Soc Nephrol. 2008;19(11):2159-69.

148. Frias F de T, de Mendonça M, Martins AR, Gindro AF, Cogliati B, Curi R, et al. MyomiRs as Markers of Insulin Resistance and Decreased Myogenesis in Skeletal Muscle of Diet-Induced Obese Mice. Front Endocrinol (Lausanne). 2016;7.

149. Wang YC, Li Y, Wang XY, Zhang D, Zhang H, Wu Q, et al. Circulating miR$130 \mathrm{~b}$ mediates metabolic crosstalk between fat and muscle in overweight/obesity. Diabetologia. 2013;56(10):2275-85. 
